\title{
RESEARCH REPORT \\ CLIMATE RESPONSE OF DAHURIAN LARCH IN SECREST ARBORETUM, WOOSTER, OHIO, USA
}

\author{
TYLER MOORE, NATHAN MALCOMB, and GREGORY WILES* \\ Department of Geology \\ The College of Wooster \\ Wooster, OH 44691, USA
}

\begin{abstract}
Larix gmelinii (Rupr.) Kuzen. (Dahurian larch) is an important arctic tree-line species in the northern boreal forests of Eurasia. The region's climate is predicted to change dramatically over the next century, yet little is known about how this species will respond to secular changes in temperature and precipitation. To this end, a ring-width chronology from 25 cores from a stand of seven Dahurian larch trees growing in the Secrest Arboretum, northeastern Ohio, was developed to test the climatic sensitivity of the species in a more temperate climate. The chronology extends from 1931 to 2005 and correlation analysis with monthly precipitation and temperature records shows growth was most strongly limited by summer precipitation until recent decades when sensitivity has shifted to late spring precipitation. The results from this study serve as a contemporary analog to the future growth response of Dahurian larch under warmer and wetter growing conditions in the boreal and arctic regions of Eurasia.
\end{abstract}

Keywords: Dahurian Larch, climate change, tree rings, season creep, Ohio.

\section{INTRODUCTION}

Regional climate projections of the Fourth Assessment Report of the Intergovernmental Panel on Climate Change predict that the species range of Larix gmelinii (Rupr.) Kuzen. var. gmelinii (Dahurian larch) in Northern Asia and the Arctic will experience a warming of $4.3-5^{\circ} \mathrm{C}$ and a likely $18 \%$ increase in precipitation by the end of the century (Christensen et al. 2007). Dahurian larch is the dominant Arctic tree line species in the boreal forests of eastern Siberia, Mongolia, northeastern China and Korea; within these regions trees occur in lowland subarctic and arctic plains, river valleys, low mountains and on edges of moors and swamps (Gower et al. 2001; Kharuk et al. 2004). The species possesses unique morphological and physiological features that enable it to withstand prolonged intervals of subzero temperatures and tremendous seasonal temperature fluctuations of greater than $100^{\circ} \mathrm{C}$

*Corresponding author: gwiles@wooster.edu
( $-64^{\circ} \mathrm{C}$ to $38^{\circ} \mathrm{C}$ ) (Kobak et al. 1996). Despite Larix gmelinii's tolerance to dynamic temperature conditions, long-term growth response to regional temperature anomalies is still unclear. Recent productivity studies suggest that larch forests currently function as net carbon sinks, but caution that warming trends may increase tree vulnerability to drought stress, fire, and insect infestation, and result in an increased carbon source (Kobak et al. 1996; Gower et al. 2001). Furthermore, dendroclimatic studies at treeline in Siberia suggest a change in the response of larch growth to warming temperatures; the sense of this change is that there is less vigorous growth than expected with the warming (Briffa et al. 1998; Vaganov et al. 1999; Jacoby et al. 2000).

Few modeling studies of boreal ecosystems have included moisture threshold and drought stress parameters and as a result, many models are likely to overestimate productivity and carbon assimilation in upper latitude forests (Melillo et al. 1993; Keeling et al. 1996; Myneni et al. 1997). Conse- 
quently, efforts to better understand growth response under temperate growing conditions would greatly improve modeling efforts.

Data are presented here to quantify the response of Dahurian larch in a temperate climate at the Secrest Arboretum of Wooster, Ohio, USA (Figure 1). In this study growth and climate response of a larch stand is assessed using ringwidth and meteorological data. Results from this baseline study will serve as an analog for possible growth trends of boreal larch forests under warmer growing conditions.

\section{SITE DESCRIPTION AND METHODS}

Samples were collected from the small, opencanopy stand of Dahurian larch in the Secrest Arboretum, on the Ohio Agricultural Research and Development Center (OARDC) campus, outside of Wooster, Ohio (Figure 1a). The stand was planted in 1929 and individual trees are 30$40 \mathrm{~cm}$ in diameter and spaced an average of four meters in a north-south grid, resulting in little competition within the stand. The sample site at $40^{\circ} 46^{\prime} 50.99^{\prime \prime} \mathrm{N}, 81^{\circ} 54^{\prime} 56.98^{\prime \prime} \mathrm{W}$ and $311 \mathrm{~m}$ a.s.l. is on a gentle grassy slope and is poorly drained (Figure 1a). Temperature and precipitation data for the dendroclimatic analysis were obtained from the Global Historical Climate Network (GHCN; Peterson et al. 1997) from the long-term meteorological station located at the OARDC, about $0.5 \mathrm{~km}$ west of the tree site (Figure 1a). Average annual temperature between 1931 and 2005 was $9.7^{\circ} \mathrm{C}$, with annual summer and winter averages of $20.9^{\circ} \mathrm{C}$ and $-2.1^{\circ} \mathrm{C}$, respectively. In contrast, Dahurian larch is naturally found in the Taiga biome north of the summer $10^{\circ} \mathrm{C}$ isotherm, with 8 months on average below $10^{\circ} \mathrm{C}$. Average annual precipitation at the OARDC between 1931 and 2005 was $930 \mathrm{~mm}$ with two thirds falling in the spring and summer months.

Twenty-five cores were taken from the seven trees using a 5-mm diameter increment borer. Core preparation and measurement was undertaken in The College of Wooster Tree-ring Laboratory where cores were prepared and dated using standard dendrochronological procedures (Stokes and Smiley 1996). After assigning calendar dates to each ring, cores were measured to the nearest $0.001 \mathrm{~mm}$ using a Velmex measuring machine. Visual and statistical cross-dating was used to ensure the accuracy of dating/ring width measurements and to assess the homogeneity of growth response amongst trees sampled in Secrest Arboretum. Statistical crossdating was performed with the aid of COFECHA (Holmes 1983; Grissino-Mayer 2003). Series intercorrelation is 0.71 , with a mean sensitivity of 0.36 and the first-order autocorrelation of 0.67 . The signal strength of the chronology was assessed using the Expressed Population Signal (EPS) statistic (Wigley et al. 1984), which suggests 0.85 as a threshold for signal strength and reliability as replication decreases through time. The larch chronology remains above a 0.90 EPS threshold for the entire study interval (1931-2005). The tree-ring series were standardized to remove geometricallyrelated growth trends (Cook and Kairiukstis 1990); this was accomplished by fitting each ring-width series with a negative exponential curve using ARSTAN (Cook 1985). Standardized indices were then averaged together using a biweight robust mean (Figure 1b, c).

To assess the climatic response of the stand, growth indices from the standard, residual and ARSTAN chronologies were compared against monthly and annual average precipitation and temperatures from the OARDC Meteorological Station by calculating the correlation coefficients between the two data sets (Figures 1,2). Because determining climate sensitivity is of primary interest in this study, standardized tree-ring indices were examined to identify intervals of growth release from canopy suppression following disturbance events in the stand. This involves the identification of average ring widths over intervals of 10 years that were at least $50-100 \%$ larger than the previous 10-year interval. Growth releases were identified using the interactive stand dynamics feature of ARSTAN and releases of greater than $50 \%$ were identified after suppressions in the mid to late 1940s, the late 1960s and 1970s, and the early 1990s (Figure 1b, c). These releases are likely linked to documented storm events and arboretum management practices (K. Cochran, personal communication 2007). In addition to the standard ring-width series we also compare the 


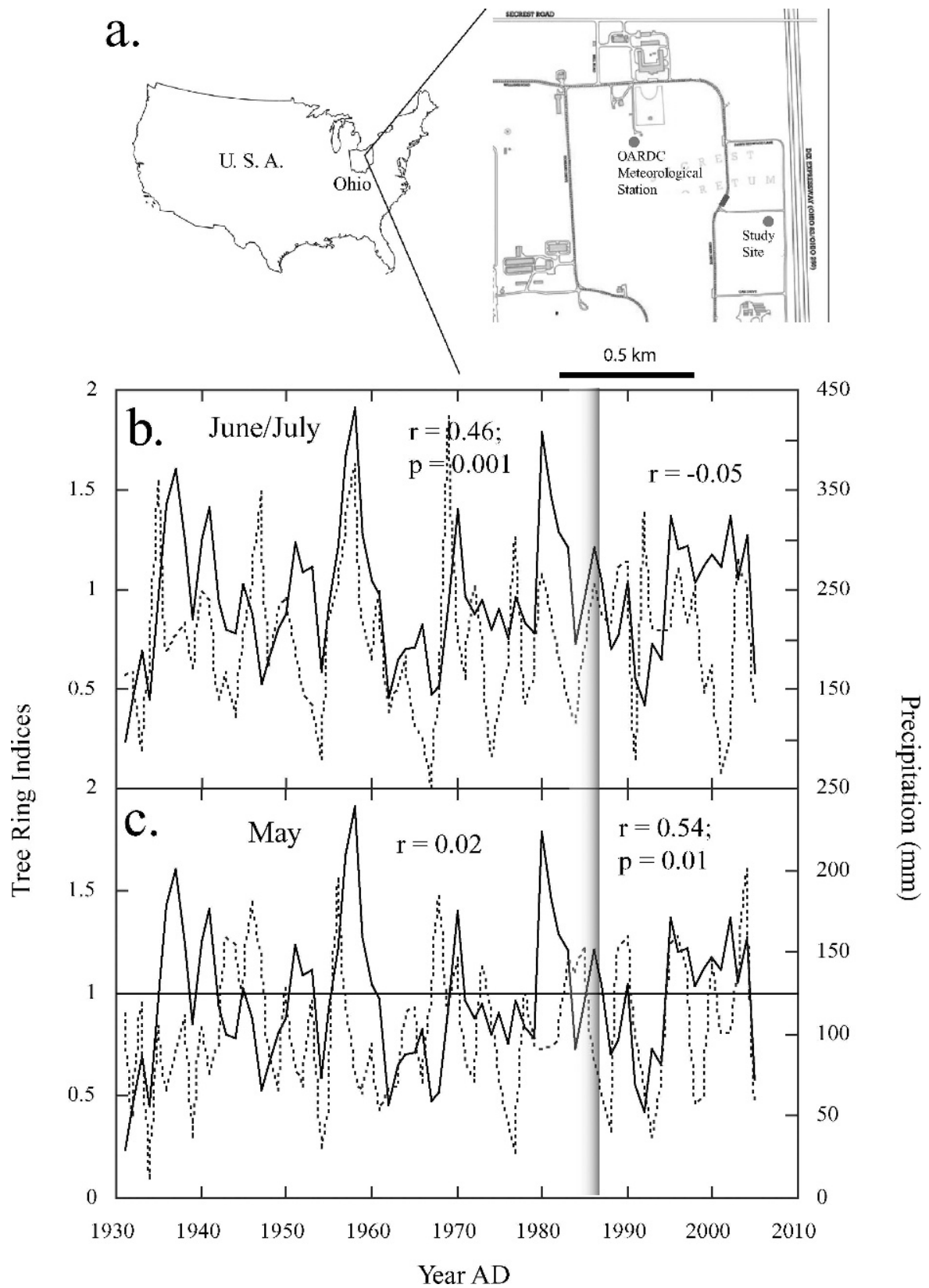

Figure 1. (a) Map of Ohio and Secrest Arboretum at the Ohio State Agricultural and Development Center in Wooster, Ohio. Note that the OARDC meteorological station is located within $0.5 \mathrm{~km}$ of the larch sample site. North is at the top on all the maps. (b) Residual tree-ring width chronology (solid line - tree-ring indices), compiled from 25 series from seven trees, compared with JuneJuly precipitation (broken line) values from the OARDC. Note the strong correlation between summer precipitation and tree growth ( $\mathrm{r}=0.46$ ) until the mid-1980s. (c) Residual tree-ring chronology compared with May precipitation values (broken line), note the increased sensitivity in recent decades $(r=0.54)$ compared with earlier lack of a relationship between tree growth and May precipitation. 
residual series with autocorrelation removed, and the ARSTAN series that reduces the influences of stand dynamics (Cook 1985).

\section{RESULTS AND DISCUSSION}

Tree ring - climate comparisons for the full 75-year period show the strongest correlations between the residual chronology and summer (June-July) precipitation $(\mathrm{r}=0.44 ; \mathrm{p}=0.001)$ (Figure 2). Correlations with precipitation and the three tree-ring series are consistent, with slightly better relationships with the residual chronology. The only significant relationship with monthly temperature values is for June $(r=-0.28, p=0.05)$. This temperature relationship may reflect increased evaporation and drought stress during warm summers. Palmer Drought Severity Indices (PDSI) values from northeast Ohio were also compared with the ring-width series and were strongest with the standard chronology $(r=0.36)$, about the same as with precipitation alone.

Summer precipitation is the dominant signal in the ring-width series and upon closer examination the relationship shows a change from summer (June-July) early in the record to late spring (May) in recent decades (Figure 1b, c). Correlations drop off abruptly after the mid 1980s as strength of response shifts from June-July to May. Spring temperatures over this interval show an increase with most of it occurring in April. This coupled with a rise in May precipitation may explain the shift, with warmer and wetter spring conditions beginning to dominate tree growth. This observation is consistent with increased tree growth earlier in the season potentially associated with a shift and an earlier start to the growing season (Root et al. 2003).

Interestingly, tree growth in some high-latitude Northern Hemispheric forests also shifts during the past several decades (D'Arrigo et al. 2007 and references therein). In the Eurasian continent, larch forests are also experiencing changes in growth patterns possibly caused by warming and associated changes. For example, Vaganov et al. (1999) and Jacoby et al. (2000) report loss of thermal sensitivity in tree growth that may be related, in part to changes in seasonality.

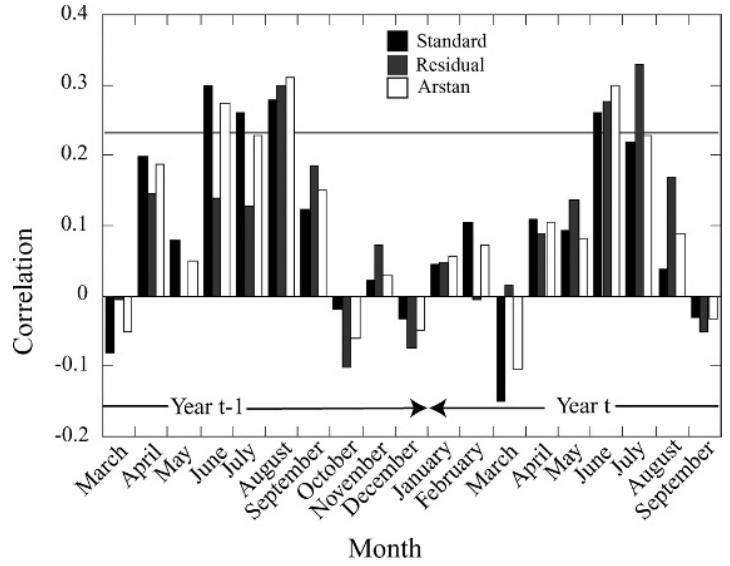

Figure 2. Nineteen-month, dendroclimatic year (March through December of the previous year and January through September of the year of growth) showing precipitation correlations with the standard, residual and ARSTAN ringwidth chronologies. The horizontal gray line shows the 0.05 confidence level for the 75-year common period.

Whereas Dahurian larch have been found to be strongly growth-rate limited by summer temperature in the boreal forests of Siberia and Northern China (Earle et al. 1994; Gower et al. 2001; Kharuk et al. 2004), summer precipitation appears to be the most important factor in modulating growth dynamics under the temperate conditions of Northeastern Ohio. In the warmer Ohio climate increased precipitation is necessary to maintain tree respiration under thermal stress. Given this relationship, future warming in the upper-latitude regions of the species' range, warming is likely to have a negative impact on forest growth and carbon assimilation if it is not accompanied by sufficient increase in precipitation. In addition, the impact of drought stress is likely to be compounded by enhanced vulnerability to fire and insect infestation (Kobak et al. 1996). Because the boreal forest is a major carbon sink, decreased productivity and increased tree mortality as a result of drought stress, insect infestation, and fire may have implications for biological processes in high-latitude boreal forests and in a broader context, the global carbon cycle (Melillo et al. 1993; Dixon et al. 1994).

These observations in a managed stand of Dahurian larch trees outside of their natural species range can yield insights about future response of tree growth to changing climate in 
the northern boreal regions. Given the apparent shift in precipitation sensitivity from summer to late spring shown in the trees of Secrest Arboretum during the 1980s, and the extremely variable nature of the stand's growth related to management and storms, the findings reported in this study, however, should be interpreted with caution. Future efforts should be directed towards identifying physiological thresholds for drought stress in Dahurian larch. This would aid in the development of more robust boreal climate/ ecosystem models that incorporate drought stress and temperature thresholds.

\section{ACKNOWLEDGMENTS}

We thank Ken Cochran of The Ohio State University for permission to sample at Secrest Arboretum and information on forest management. We also thank Neil Pederson and one anonymous reviewer for comments that greatly improved this work. Alex Trutko helped in the sampling.

\section{REFERENCES CITED}

Briffa, K., F. Schweingruber, P. Jones, and T. Osborn, 1998. Reduced sensitivity of recent tree growth to temperature at high northern latitudes. Nature 391:378-682.

Christensen, J. H., B. Hewitson, A. Busuioc, A. Chen, X. Gao, I. Held, R. Jones, R. K. Kolli, W.-T. Kwon, R. Laprise, V. Magaña Rueda, L. Mearns, C. G. Menéndez, J. Räisänen, A. Rinke, A. Sarr, and P. Whetton, 2007. Regional climate projections. In Climate Change 2007: The Physical Science Basis. Contribution of Working Group I to the Fourth Assessment Report of the Intergovernmental Panel on Climate Change, edited by S. Solomon, D. Qin, M. Manning, Z. Chen, M. Marquis, K. B. Averyt, M. Tignor, and H. L. Miller, Cambridge University Press, Cambridge, United Kingdom, and New York, New York, USA.

Cook, E. R., 1985. A Time Series Approach to Tree-Ring Standardization. Ph.D. dissertation, University of Arizona, Tucson.

Cook, E. R., and L. Kairiukstis, 1990. Methods of Dendrochronology. Applications in the Environmental Sciences. Dordrecht Kluwer Academic Publishers, 394 pp.

D’Arrigo, R., R. S. Wilson, B. Liepert, and P. Cherubini, 2007. On the 'divergence problem' in northern forests: A review of the tree-ring evidence and possible causes. Global and Planetary Change. doi: 10.1016/j.gloplacha.2007.03.004.
Dixon, R., A. Solomon, S. Brown, R. Houghton, M. Trexier, and J. Wisniewski, 1994. Carbon pools and flux of global forest ecosystems. Science 263:185-190.

Gower, S., O. Krankina, R. Olson, M. Apps, S. Linder, and L. Wang, 2001. Net primary production and carbon allocation patterns of boreal forests. Ecological Applications 11: 1395-1411.

Grissino-Mayer, H. D., 2003. Evaluating crossdating accuracy: A manual and tutorial for the computer program COFECHA. Tree-Ring Research 57:205-221.

Earle, C., L. Brubaker, A. Lozhkin, and P. Anderson, 1994. Summer temperature since 1600 for the upper Kolyma Region, Northeastern Russia, reconstructed from tree-rings. Arctic and Alpine Research 26:60-65.

Holmes, R., 1983. Computer-assisted quality control in treering dating and measurement. Tree-Ring Bulletin 43:69-78.

Jacoby, G. C., N. Lovelius, O. Shumilov, O. Raspopov, J. Kurbainov, and D. Frank, 2000. Long-term temperature trends and tree growth in the Taymir region of northern Siberia. Quaternary Research 53:312-318.

Keeling, C., J. Chin, and T. Whorf, 1996. Increased activity of northern vegetation inferred from atmospheric $\mathrm{CO} 2$ measurements. Nature 382:146-149.

Kharuk, V., M. Dvinskaya, K. Ranson, and S. Im, 2004. Expansion of evergreen conifers to the larch-dominated zone and climatic trends. Russian Journal of Ecology 36:164-170.

Kobak, K., Y. Turcmnovich, N. Kondrasiheva, E. Schulze, D. Schulze, H. Koch, and N. Vygodskay, 1996. Vulnerability and adaptation of the larch forest in eastern Siberia to climate change. Water, Air, \& Soil Pollution 92:119-127.

Melillo, J., A. McGuire, D. Kicklighter, B. Moore, C. Vorosmary, and A. Schloss, 1993. Global climate change and terrestrial net primary production. Nature 363:234-240.

Myneni, R., C. Keeling, C. Tucker, G. Astar, and R. Nemani, 1997. Increased plant growth in the northern high latitudes from 1981-1991. Nature 386:698-702.

Peterson, T. C., and R. S. Vose, 1997. An overview of the global historical climatology database. Bulletin of the American Meteorological Society 78:2837-2849.

Root, T. L., J. T. Price, K. R. Hall, S. H. Schneider, C. Rosenzweig, and J. A. Pound, 2003. Fingerprints of global warming on wild animals and plants. Nature 421:57-60.

Stokes, M., and T. Smiley, 1996. An Introduction to Tree-Ring Dating. The University of Arizona Press, Tucson.

Vaganov, E., Hughes, M., Kirdyanov, A., Schweingruber, F., and Silkin, P., 1999. Influence of snowfall and melt timing on tree growth in Subarctic Eurasia. Nature 400:149-151.

Wigley, T. M., K. R. Briffa, and P. D. Jones, 1984. On the average value of correlated time series with applications in dendroclimatology and hydrometeorology. Journal of Climatology and Applied Meteorology 23:201-213.

Received 7 June 2007; Accepted 9 September 2007. 